\title{
Evaluation of Personal Solar UV Exposure in a Group of Italian Dockworkers and Fishermen, and Assessment of Changes in Sun Protection Behaviours After a Sun-Safety Training
}

Alberto Modenese ${ }^{1, *}$, Fabio Bisegna ${ }^{2}$, Massimo Borra ${ }^{3}$, Giulia Bravo ${ }^{4}$, Chiara Burattini ${ }^{2}$, Anna Grasso ${ }^{1}$, Luca Gugliermetti ${ }^{2}$, Francesca Larese Filon ${ }^{5}$, Andrea Militello ${ }^{3}$, Francesco Pio Ruggieri ${ }^{1}$, Fabriziomaria Gobba ${ }^{1}$

${ }^{1}$ Department of Biomedical, Metabolic and Neural Sciences, University of Modena and Reggio Emilia, Modena, 41125, Italy

${ }^{2}$ Department of Astronautical, Electrical and Energy Engineering, University of Rome "Sapienza", Rome, 00184, Italy

${ }^{3}$ Department of Occupational and Environmental Medicine, Epidemiology and Hygiene, Italian Workers' Compensation Authority (INAIL-DiMEILA), Monte PorzioCatone (Rome), 00078, Italy

${ }^{4}$ Department of Medicine, University of Udine, Udine, 33100, Italy

${ }^{5}$ Unit of Occupational Medicine, University of Trieste, Trieste, 34128, Italy

A R T I C L E I N F O

Article history:

Received: 23 December, 2020

Accepted: 30 January, 2021

Online: 28 February, 2021

Keywords:

Solar ultraviolet radiation

Occupational exposure

Maritime workers

\begin{abstract}
A B S T R A C T
Solar ultraviolet radiation (UVR) is considered a relevant health risk for the workers of the maritime and port sectors, but scant data are available on actual exposure measured using personal dosimeters. Moreover, in outdoor workers sun protection habits are usually poor, while some promising data suggest that sun-safety campaigns can be effective in increasing self-protection at work. Accordingly, our aim was to conduct an assessment of solar UVR exposure in dockworkers and fishermen using personal dosimeters, and to evaluate the use of sun protection measures at work after a sun-safety training. We performed two different UVR measurements campaigns in spring-summer 2018, investigating 7 fishermen and 14 dockworkers. Electronic dosimeters have been placed on the workers for at least a half work-day. Only at the port it was also possible to register the environmental UVR exposure with a specrto-radiometer, while for fishermen we estimated the corresponding environmental exposure using an algorithm. Our results demonstrate a high erythemal UVR dose received by the workers, with an individual exposure up to $542 \mathrm{~J} / \mathrm{m} 2$ for fishermen in spring and up to $1975 \mathrm{~J} / \mathrm{m} 2$ for dockworkers in summer. This data indicates an excessive occupational risk, needing more effective prevention. Accordingly, we offered a sun-safety training to the workers. Before the training, protective behaviour of the workers was rather poor: about the 50\% never used the hat, the 40\% never wore sunglasses and none of the workers referred to apply sunscreens at work. After the training, fishermen reported a relevant improvement in the use of individual UV protections, as hat (+9.6\%), sunglasses $(+28.5 \%)$ and clothes $(+5 \%)$, even if the use of sunscreens at work was not increased.
\end{abstract}

\section{Introduction}

Solar ultraviolet radiation (UVR) exposure represents an important occupational risk in the maritime and port sectors: this paper is an extension of work originally presented in the 2020 IEEE International Conference on Environment and Electrical Engineering and 2020 IEEE Industrial and Commercial Power

\footnotetext{
"Corresponding Author: Alberto Modenese, Email: alberto.modenese@unimore.it
}

Systems Europe (EEEIC / I\&CPS Europe) [1], integrated with data we published elsewhere [2], further elaborated and with additional inclusion of new results.

The possible adverse health effects occurring in workers exposed to solar UVR include both acute and long-term ones and mainly involve the skin and the eyes. The consequences may be severe, as in the case of cancers: solar UVR is considered the most frequent occupational carcinogenic exposure [3], for its ability to 
induce in particular non-melanoma skin cancers (NMSC) [4], but also some forms of melanoma skin cancers may be related to occupational UV exposure [5], as well as rare forms of eye tumors, as the squamous cell carcinomas of the cornea and conjunctiva and ocular melanomas [6]. Considering the skin, other frequent adverse health conditions associated with cumulative solar UV exposure, and representing precancerous lesions, are photo-aging and actinic keratosis [7]. Regarding the eyes, it should be noted that usually this organ is much more protected from UV rays compared to the skin, for anatomical reasons and for the actions of various involuntary reflexes (pupillary reflex, squinting, winking) [8]. Nevertheless, UV eye exposure may be relevant in particular conditions, as in the case of UV rays reflected from surfaces like polished metal, water, snow, white sand and marbles, etc [8]. Fishermen and dockworkers, often close to the water, may be at particular risk for relevant UV eye exposure. In addition to the eye tumors, there are various ocular diseases recognizing solar UVR as a risk factor: among all, cataract [6], currently the leading cause of visual impairment worldwide [9]; pterygium, a hyperplasia of the bulbar conjunctiva highly correlated with increased levels of UV radiation [6]; and possibly also age-related macular degeneration [6], a chronic degenerative retinal disease, the second leading cause of blindness in the world [9]. For all these three eye pathologies, positive significant associations with solar radiation exposure and increased risks for outdoor workers of being diagnosed with the diseases have been well documented [10-12].

Despite the recognized health risk, there are scant studies investigating solar UVR exposure levels in the maritime and port sector [2,13-15]. Fishermen spend most of their working time outdoor on the boats, close to the water surface, reflecting a relevant amount of UVR [8]; but also dockworkers, in particular those working at the quay, are almost always outside and quite often close to reflecting surfaces, such as water, but also lucid metallic surfaces on the quay/ships. According to these considerations, it is certainly of interest a detailed assessment of solar UVR exposure of these groups of workers. Furthermore, the extant scientific literature shows a relevant under-estimation of the risk by outdoor workers, with indications of poor protective habits and behaviors with respect to a relevant occupational risk, which is solar UVR exposure [16-22]. There is also a growing evidence that sun-safety interventions are effective in increasing outdoor workers' sun-protection habits [21]; nevertheless, there is still a scarcity of these interventions focused on outdoor workers, and in particular on those of the maritime and port sectors.

Our objective is to report the results of two different solar UVR measurements campaigns, respectively performed in a group of Italian dockworkers and fishermen, and a subjective evaluation of sun-exposure in a sub-group of the workers. Moreover, we wanted to test the possible improvement of the use of sun protections one year after our measurement's campaigns, including specific sunsafety trainings.

\section{Materials and Methods}

\subsection{The solar UV radiation measurements campaigns}

We registered personal exposure to solar UVR with electronic dosimeters during two different campaigns involving two groups of outdoor workers: fishermen (FM) and dockworkers (DW). Both the groups were voluntary recruited respectively from a fishing and a port company active in the area of the north-east of Italy, on the Adriatic sea (coordinates: $43^{\circ} 9^{\prime} \mathrm{N}, 12^{\circ} 7^{\prime}$ E for FM; $45^{\circ} 4^{\prime} \mathrm{N}, 13^{\circ}$ $5^{\prime}$ E for DW). Considering the unstable whether conditions and the job activities mainly in the morning, we monitored FM for two consecutive spring days (15-16 May 2018), while for DW we registered personal solar UVR exposure during a summer day, with almost sunny wheather (4 July 2018). The personal electronic dosimeter used were 10 devices of the Gigahertz-Optik X2000 and X2012 series, while for a reference of the environmental erythemal UV dose in the monitored days we consulted the free online database of the Troposhpheric Emission Monitoring Internet Service (TEMIS) of the European Space Agency, as described in detail in our previous works [1,2]. Briefly, the TEMIS website provides daily erythemal UV dose data for various places of the world; the data provided are derived by means of radiative transfer calculation codes from satellite measurements, considering local meteorological variables; such data were used to calculate the local environmental radiant exposure referred to the horizontal surface plane. The closest location to the dosimetry campaigns for which effective irradiance data have been made available is Venice, in Italy, that was selected as a proxy, being less than $200 \mathrm{~km}$ northeast compared to the workplace of the fishermen, and approximately $160 \mathrm{~km}$ south-west considering the port of the dockworkers. Erythemal UVR dose in Venice was $2.6 \mathrm{~kJ} / \mathrm{m}^{2}$ on $15^{\text {th }}$ May, $3.6 \mathrm{~kJ} / \mathrm{m}^{2}$ on $16^{\text {th }}$ May and $4.7 \mathrm{~kJ} / \mathrm{m}^{2}$ on $4^{\text {th }} \mathrm{July}$. For dockworkers, we used this data only as comparison, as we registered the local erythemal radiant exposure on the horizontal surface with a Gigahertz-Optik BTS2048-UV-S spectroradiometer placed at the quay. For fishermen it was not possible to use the spectro-radiometer on the boats, and we applied a formula [2] to reconstruct the percentage of ambient UVR received by the workers. For all the workers, the dosimeters were mainly placed on the upper back, that was the position we found most comfortable in order to not interfere with the job activities. In some cases we were able to put the devices on the chest of the workers, and only for a fisherman we had the possibility to attach the meter on the back side of his cap to simulate nape exposure (Fig. 1).

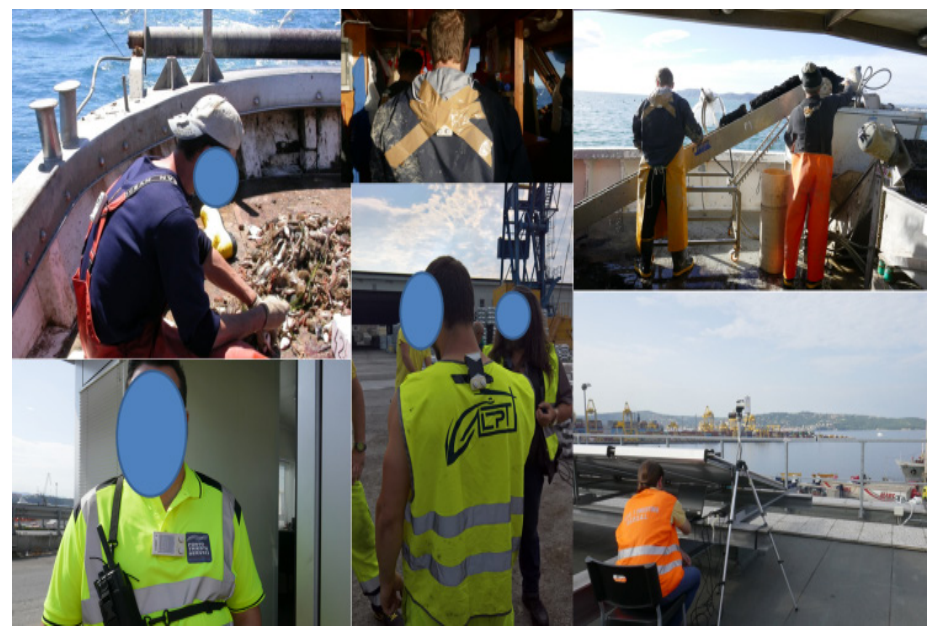

Figure 1: Placement of the UV electronic dosimeters at the workplace, on the fishermen (FM) and dockworkers (DW). From left to right, top to bottom: (1) a FM with a dosimeter on the back and one on the cap to simulatenape exposure; (2) a FM with a back dosimeter working in a covered area of the boat;(3) two FM with back dosimeters working in an uncovered area of the boat; (4) a DW working as port coordinator with a chest dosimeter; (5) a DW working as longshoreman with a 
dosimeter on the upper back; (6)spectroradiometer for ambient solar UV dose measurements placed at the quay of the port.

The measurements were organized within a preventive campaign for the evaluation of the occupational risks in various occupational activities according to the Italian national occupational health and safety legislation, and were also aimed to the development of more adequate information and training of the workers. All the ethic principles considered in the Helsinki declaration were followed.

\subsection{The sun exposure habits and protective behaviors investigation and the sun safety intervention}

Only for the fishermen, between the two consecutive days of the measurements campaign we were able to collect a selfadministered questionnaire, investigating personal solar UVR exposure habits and protecting behaviors during work and leisure activities, previously described [18]. Briefly, the 22 items questionnaire has two sections, one for work and one for leisure exposure; questions investigate the type of outdoor activity and the protections adopted to reduce solar UVR exposure. With the purposes of evaluating possible improvements of sun protection habits and behaviours at work after a sun safety training, we analyzed the results related to four items investigating the frequency of adoption of individual protections at work: use of UV protective hat, sunglasses with UV filtering lenses, UV protective clothes and sunscreens protections. Workers were asked to answer mainly on a 5 point Likert scale (from 0, meaning "never adopted the exposure habit/protective behavior", to 5 "always adopted the exposure habit/protective behavior"). The questionnaire was collected before a four-hours sun-safety training, explaining to the workers the characteristics of the solar UVR risk, the methods to evaluate the risk, the possible adverse health effects associated to solar UVR exposure and the importance of prevention during outdoor work practices, including the use of individual protections. The training was performed by the same experts involved in the measurements campaigns, for both DW and FM, but, as previously mentioned, the questionnaire was collected only for FM. The group of FM who participated in the training was larger compared to the workers we individually investigated with our dosimeters during the measurements campaigns. We decided to administer the questionnaire before the training, i.e. before the workers received any information on solar UVR risk that could be able to influence their answers. Then, one year after the measurements campaigns and the sun-safety training (May 2019), we contacted via phone the fishermen who participated in the sun-safety training and we adminstered the same questionnaire, in order to evaluate a possible improvement of the protective habits and behaviors of the workers, to be possibly attributed to the intervention we performed.

\section{Results}

\subsection{Results of the solar UV radiation measurements campaigns}

We measured individual solar UVR exposure of 7 fishermen and 14 dockworkers, all males (Table 1). FM worked on three fishing boats with different characteristics with respect to the availability of protections against solar radiation: one medium size boat (B1), only partially covered, but with various tasks of the work activity (mussel fishing) performed in shielded areas, one small boat (B2), with almost no coverage from UVR, for activities (sea snails and cuttlefish fishing) performed in direct sunlight and another medium size boat (B3), partially covered, with only parts of the activities (trawling fishing) in direct sun. Considering DW, 10 of them worked as longshoremen (LSM) almost always close to the quay and to the water, while 4 subjects worked as coordinators of the port traffic (traffic coordinator, TC), with some activities performed inside a small office (Table 1).

Table 1: Results of individual measurements of occupational solar UVR exposure for 7 fishermen and 14 dockworkers from the North-East of Italy.

\begin{tabular}{|c|c|c|c|c|c|c|}
\hline \multicolumn{2}{|c|}{$\begin{array}{l}\text { Work place / job } \\
\text { task }\end{array}$} & \multirow[t]{2}{*}{$\begin{array}{c}\text { Placement } \\
\text { of the } \\
\text { dosimeter }\end{array}$} & \multirow[t]{2}{*}{$\begin{array}{c}\text { Working } \\
\text { period / } \\
\text { length of } \\
\text { the period } \\
\text { measured } \\
\text { (minutes)* }\end{array}$} & \begin{tabular}{|l} 
Personal \\
UV \\
erythemal \\
dose \\
$\left(\mathrm{J} / \mathrm{m}^{2}\right)^{*}$
\end{tabular} & \begin{tabular}{|c|} 
Ambient \\
UV \\
effective \\
radiant \\
exposure \\
$\left(\mathrm{H}_{\text {eff }}\right)$ \\
$\left(\mathrm{J} / \mathrm{m}^{2}\right)^{* \pm}$
\end{tabular} & $\begin{array}{c}\text { Personal } \\
\text { erythemal } \\
\text { vs. } \\
\text { ambient } \\
\text { UVR } \\
\text { exposure } \\
(\%) * \pm\end{array}$ \\
\hline \multirow{3}{*}{ B1 } & FM1 & & & 213 & \multirow{3}{*}{1710} & 12.5 \\
\hline & FM2 & Back & morning / & 79 & & 4.6 \\
\hline & FM3 & Back & & 71 & & 8.8 \\
\hline \multirow[t]{2}{*}{ B2 } & FM4 & $\begin{array}{c}\text { Back (\& } \\
\text { Nape) } \\
\end{array}$ & \multirow{2}{*}{$\begin{array}{c}\text { morning / } \\
180\end{array}$} & $\begin{array}{c}542 \\
(380) \\
\end{array}$ & \multirow[t]{2}{*}{830} & $\begin{array}{c}65.3 \\
(45.8) \\
\end{array}$ \\
\hline & FM5 & Back & & 288 & & 34.7 \\
\hline \multirow[b]{2}{*}{ B3 } & FM6 & Back & \multirow[b]{2}{*}{$\begin{array}{c}\text { morning / } \\
300\end{array}$} & 151 & \multirow[b]{2}{*}{1560} & 9.7 \\
\hline & FM7 & $\begin{array}{c}\text { Back (\& } \\
\text { chest) }\end{array}$ & & $\begin{array}{l}129 \\
(98)\end{array}$ & & $\begin{array}{c}8.3 \\
(7.8)\end{array}$ \\
\hline \multirow{10}{*}{ Quay } & $\begin{array}{c}\text { DW1- } \\
\text { LSM }\end{array}$ & Back & \begin{tabular}{|c|} 
full-day / \\
432
\end{tabular} & 1975 & 3339 & 59 \\
\hline & $\begin{array}{c}\text { DW2- } \\
\text { LSM }\end{array}$ & Back & \begin{tabular}{|c|} 
full-day / \\
417 \\
\end{tabular} & 1067 & 3276 & 32 \\
\hline & \begin{tabular}{|c|} 
DW3- \\
LSM \\
\end{tabular} & Back & \begin{tabular}{|c|} 
morning / \\
144
\end{tabular} & 288 & 857 & 33 \\
\hline & \begin{tabular}{|c|} 
DW4- \\
LSM
\end{tabular} & Back & $\begin{array}{c}\text { morning / } \\
191\end{array}$ & 402 & 1322 & 30 \\
\hline & $\begin{array}{c}\text { DW5- } \\
\text { LSM } \\
\end{array}$ & Chest & \begin{tabular}{|c|} 
morning / \\
243 \\
\end{tabular} & 257 & 1596 & 16 \\
\hline & $\begin{array}{c}\text { DW6- } \\
\text { LSM }\end{array}$ & Back & $\begin{array}{c}\text { morning / } \\
251 \\
\end{array}$ & 854 & 1965 & 43 \\
\hline & $\begin{array}{l}\text { DW7- } \\
\text { LSM }\end{array}$ & Back & \begin{tabular}{|c|} 
morning \\
\& early \\
afternoon \\
$/ 260$ \\
\end{tabular} & 551 & 2675 & 20 \\
\hline & $\begin{array}{c}\text { DW8- } \\
\text { LSM } \\
\end{array}$ & Back & \begin{tabular}{|c|} 
afternoon \\
$/ 246$ \\
\end{tabular} & 622 & 2191 & 28 \\
\hline & \begin{tabular}{|c|} 
DW9- \\
LSM \\
\end{tabular} & Back & \begin{tabular}{|c|} 
afternoon \\
$/ 226$ \\
\end{tabular} & 458 & 2001 & 22 \\
\hline & $\begin{array}{c}\text { DW10- } \\
\text { LSM }\end{array}$ & Back & \begin{tabular}{|c|}
$\begin{array}{c}\text { afternoon } \\
/ 225\end{array}$ \\
\end{tabular} & 413 & 1981 & 20 \\
\hline \multirow{4}{*}{$\begin{array}{l}\text { Center } \\
\text { of the } \\
\text { port } \\
\text { (partially } \\
\text { indoor) }\end{array}$} & $\begin{array}{c}\text { DW11- } \\
\text { TC }\end{array}$ & Chest & \begin{tabular}{|c|} 
morning / \\
177 \\
\end{tabular} & 48 & 1550 & 3 \\
\hline & \begin{tabular}{|c} 
DW12- \\
TC \\
\end{tabular} & Chest & \begin{tabular}{|c|} 
Morning / \\
193 \\
\end{tabular} & 139 & 1759 & 7 \\
\hline & $\begin{array}{c}\text { DW13- } \\
\text { TC }\end{array}$ & Chest & $\begin{array}{c}\text { Afternoon } \\
/ 210\end{array}$ & 89 & 1876 & 4 \\
\hline & \begin{tabular}{|c} 
DW14- \\
TC \\
\end{tabular} & Chest & $\begin{array}{c}\text { Afternoon } \\
/ 248\end{array}$ & 44 & 2045 & 2 \\
\hline
\end{tabular}

Legend: $B 1=$ boat 1 , middle-size, partially covered; $B 2=$ boat 2 , small size, no coverage; $B 3=$ boat 3 , partially covered; $F M=$ fisherman; $D W=$ dockworker; $L S M=$ longshoreman; $T C=$ traffic coordinator. ${ }^{*}=$ for fishermen the worst exposure scenario occurred in one of the two days with measurements is reported in the Table; ${ }^{ \pm}=$for fishermen, ambient exposure was estimated according to a specific formula [2] 
Regarding the length of the individual measurements period, unfortunately for almost all the workers it was not possible to monitor an usual full working day, as FM started their work-shifts few hours before sunrise, so that measuring UVR in that period was meaningless, and they finished between 1:00-2:00 p.m.; considering DW, for the large majority of them the activities were organized on separate morning and afternoon work-shifts, and only two DW worked both in the morning and in the afternoon the day we performed our measurements.

Considering the worst exposure scenario for the seven fishermen during the two days monitored, we found personal UVR exposure at the back ranging between $71 \mathrm{~J} / \mathrm{m}^{2}$ registered for FM3 working on the B1 and 542 for FM4 on the B2. The estimated proportion of environmental erythemal UVR dose received on the back of the FM resulted between a minimum of $4.6 \%$ for FM2 on the B1 and a maximum of $65.3 \%$ for FM4 on the B2 (Table 1).

Considering DW, we collected personal solar UVR exposure data at the back for LSM while at the chest for the TC, as they had quite often to sit inside a small office in the middle of the port area. The results of the measurements show a higher exposure in LSM compared to TC: the highest exposure of $1975 \mathrm{~J} / \mathrm{m}^{2}$ was collected, not surprisingly, for one of the two LSM (DW1) who worked for a full day (approximately 7 hours and a half). The individual exposure of the other LSM ranged between $257 \mathrm{~J} / \mathrm{m}^{2}$ collected at the chest of DW5 (i.e. the oly LSM with a chest dosimeter, who was monitored for more than four hous in the morning) and 1067 $\mathrm{J} / \mathrm{m}^{2}$ for the other LSM who was monitored for approximately seven hours (DW2). For the other LSM with dosimeters on the back and monitored only in the morning or afternoon, exposures resulted between $288 \mathrm{~J} / \mathrm{m}^{2}$ measured in the morning in about two hours and a half (DW3) and $854 \mathrm{~J} / \mathrm{m}^{2}$ registered again in the morning but in more than four hours (DW6). Percentages of ambient exposure received by the LSM varied between the 16 and the $59 \%$. Considering TC, their individual solar UVR exposures at the chest varied between $44 \mathrm{~J} / \mathrm{m}^{2}$ measured in about four hours in the afternoon (DW14) and $139 \mathrm{~J} / \mathrm{m}^{2}$ registered in approximately three hours in the morning (DW12), with percentages of individual versus ambient exposure between the 2 and the $7 \%$ (Table1).

\subsection{Results of the investigation of sun exposure habits and protective behaviors among fishermen}

Twenty-one fishermen, all males, participated in the sunsafety training we proposed to the fishing company where we performed the individual solar UVR measurements campaign. We administered our questionnaire investigating sun exposure habits and behaviours before the starting of the training, and all of them filled-in the questionnaire. The $47.7 \%$ of the FM reported to never use an UVR protective hat at work. The $38.1 \%$ of them never used UV filtering sunglasses on the boats. None of the workers reported to use. always, often or even sometimes, sunscreens at work. Only for the clothes we collected some positive responses: the $40 \%$ of the sample wore often protective clothes (Table 2). After one year from the sun safety training we contacted all the 21 fishermen via phone, asking them the same questions related to the frequency of adoption of solar UVR individual protections at work.
Table 2: Results of the subjective investigation on the frequency of adoption of solar UVR individual protections at work among 21 fishermen

\begin{tabular}{|c|c|c|c|c|}
\hline \multicolumn{5}{|c|}{ Individual protecions against solar UVR } \\
\hline $\begin{array}{c}\text { Frequency of } \\
\text { adoption on a } \\
\text { 5-point Likert } \\
\text { scale }\end{array}$ & \multicolumn{4}{|c|}{ Fishermen adopting the individual } \\
protection: \% (n) \\
\hline & $\begin{array}{c}\text { Protective } \\
\text { hat }\end{array}$ & $\begin{array}{c}\text { UV } \\
\text { filtering } \\
\text { sunglasses }\end{array}$ & $\begin{array}{c}\text { Protective } \\
\text { clothes* }\end{array}$ & Sunscreens \\
\hline ALWAYS & $14.3(3)$ & $14.3(3)$ & $15(3)$ & 0 \\
\hline OFTEN & $19(4)$ & $9.5(2)$ & $40(8)$ & 0 \\
\hline SOMETIMES & $19(4)$ & $14.3(3)$ & $25(5)$ & 0 \\
\hline SELDOM & 0 & $23.8(5)$ & $15(3)$ & $19(4)$ \\
\hline NEVER & $47.7(10)$ & $38.1(8)$ & $5(1)$ & $81(17)$ \\
\hline
\end{tabular}

*1 answer was missing

In order to better appreciate the differences between the answers given before and after the training, we grouped together as positive responses the answers "always", "often" and "sometimes" and we analyzed the percentage of FM who reported to adopt UV protections at the baseline and one year after the sunsafety campaign (Fig. 2). After the sun-safety interventions there was an improvement of the $9.6 \%$ for the use of UV protective hat at work, of the $28.5 \%$ for the use of UV filtering sunglasses (with a significant difference at the non-parametric McNemar statistical test for paired nominal data, $\mathrm{p}=0.031$ ) and of the $5 \%$ for the wearing of UV protective clothes. No improvements have been found for the use of sunscreens at work by the fishermen (Fig. 2).

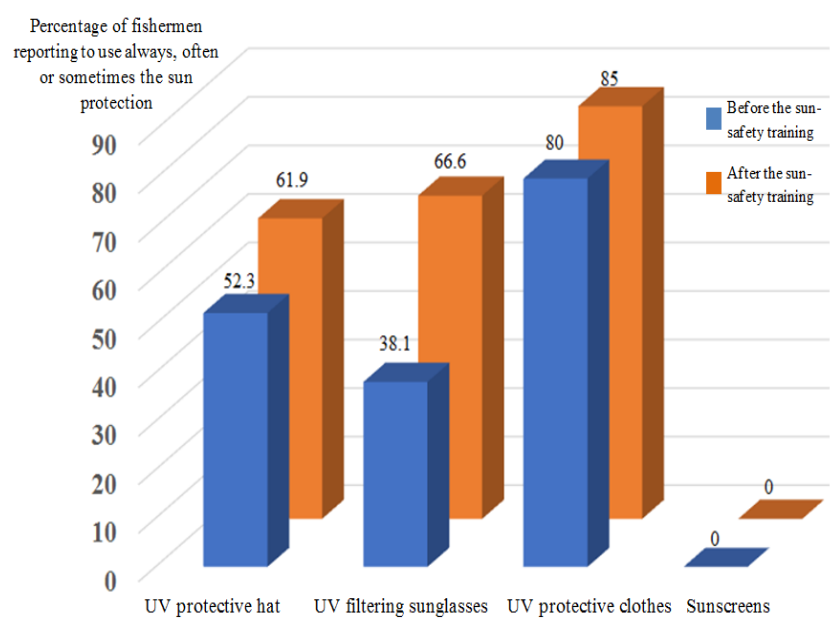

Figure 2: Use of individual solar UVR protections at work before and one-year after the sun-safety training in a group of 21 fishermen.

\section{Discussion}

Our results on personal solar UVR exposure measured in a group of dockworkers and fishermen of North-East Italy show remarkable high UV exposure levels. For FM we collected measures in late spring, while for DW in summer: not surprisingly, the exposure levels we detected resulted higher in the case of DW. Nevertheless, even if the two days of the measurements campaign for the FM were partially clouded spring days, we registered, in less than five hours on average, an exposure above the equivalent of a Standard Erythemal Dose (SED, i.e. an UVR personal 1315 
exposure able to induce an erythema in an individual, adjusted for skin pigmentation, and corresponding approximately to $100 \mathrm{~J} / \mathrm{m}^{2}$ ) in all but two FM, with a maximum exposure of more than 5 SEDs/day. This indicates a very high risk of acute skin burns, and, considering the photochemical accumulation of UV-induced damages, may also represent an increased risk for long-term adverse health effects, in case of exposures prolonged over years. Considering the specific work tasks, the FM were involved in three different types of fishing performed on three different boats. We collected the highest exposure levels on the smallest boat, with almost no coverage from the solar UV rays, dedicated to an activity (sea snails and cuttlefish fishing) performed almost always in direct sunlight.

Considering now the DW, also in this case we measured different solar UVR exposure levels depending on the specific type of work activity performed. We registered higher solar UVR individual levels for longshoremen compared to traffic coordinators. The personal UV doses collected for LSM, in the $90 \%$ of the cases with dosimeters placed on their upper back, varied between 2.6 SED/half-day and $20 \mathrm{SED} /$ day. Also, for the LSM investigated with a chest dosimeter we registered a quite high exposure of $5.5 \mathrm{SED} /$ half-day. Considering dockworkers employed as TC, we had to place the dosimeters on their chests, as they frequently had to be seated at a desk inside a small cabin office, therefore performing also partially indoor activities. For TC we measured exposures between 0.4 and $1.4 \mathrm{SED} /$ half-day.

Discussing now the relations between individual and environmental solar UVR skin exposure, we found quite high variability both in the results related to FM and in those collected for DW. This variability is not surprising and reported also in other studies of personal solar UVR eposure measurements in outdoor workers [14,23-28]. It can be related to the different working postures adopted by the workers and to other factors, as the sunangle on the horizon, the distance from reflecting surfaces (e.g. water) and the presence of shading structures: accordingly, the exposure of different body districts can change during the day in relation to the ways the activity is performed and to the environment. Percentages of individual vs. environemtal UVR exposure varied between the 4.6 and the $65.3 \%$ for FM, $20.6 \%$ on average including only data retrieved for dosimeters placed on the backs. For longshormen, the average percentage of ambient exposure received at the workers' backs was of $31.9 \%$, with a maximum of 59 and a minimum of the $20 \%$,dropping to the $16 \%$ considering the LSM with a chest dosimeter. It should be noted a lower variability of the results related to the solar radiation exposure of dockworkers employed as port traffic coordinators compared to fishermen and longshoremen. A possible reason is that the activity of the TC is less dynamic compared to that of the other groups: for these workers we found a percentage of personal vs. ambient exposure between the 2 and the $7 \%$, almost stable and quite low, considering that the dosimeters in these cases were placed on the chest and that some working tasks of the workers were performed in an indoor area.

As regards to the results of the investigation on solar UVR individual exposure habits and behaviours before and after a specific sun-safety training, first of all it should be noted that, to the best of our knowledge, this is the first reporting of a sun safety initiative specifically addressing fishermen. As reported also by similar studies performed in other groups of outdoor workers [1620], our results indicate poor protective habits and behaviors of fishermen, in particular before the sun-safety training. After our intervention, we observed a slight improvement related to the adoption of three specific individual protections: the UV protective hats, sunglasses and clothes, with an increased percentage of fishermen who reported to use, at least sometimes, these protections at work. This is still far from an adequate perception of the risk, as even after our sun-safety campaign approximately the $35-40 \%$ of the workers never or only seldom reported to use hats and sunglasses at work, while more adequate habits have been reported for protective clothes. Unfortunately, our intervention apparently failed in raising the awareness of the group of fishermen on the importance of applying sunscreens at work: this is a relevant point, and we should reflect on what can be the issues in achieving the goal of a more widespread use of sunscreens at work. Some possible problems may be related to the quite high costs of the sunscreens, in particular considering that they have to be abundantly applied and re-applied during the work-day, and to the fact that, at least in Italy, these costs are usually not covered by the companies. Nevertheless, it should also be noted that sunscreens can't be considered personal protective equipment as UV protective hats, sunglasses and clothes, but they are an additional protective measure to be adopted in case the other personal protections can't be considered sufficient to limit the exposure.

Our study also has some limitations: first of all, the sample size, in particular in the case of the fishermen, where we collected solar UVR exposure data of only seven workers: nevertheless, having followed the workers for two days, and in some cases with two dosimeters per worker, we retrieved a total number of nineteen point measurements, i.e. even more measurements compared to the campaign performed at the port, where we investigated fourteen dockworkers in only one day. Also, for the subjective investigation of solar UVR exposure habits and behaviours the sample of twentyone subjects can be considered of a quite small size: in this case, a relevant point, possibly reducing the limitation, is that we were able to re-contact all the investigated workers after one year, and accordingly our analysis of the changes in protective behaviours after our sun-safety training resulted more valid.

A further limitation is related to the estimate of the environmental UVR doses for the measurement campaign in the fishing company. Unfortunately, we performed ambient measurements with an UVR spectro-radiometer only at the harbour, where it was possible to safely place the instrumentation in a stable site. This was not possible on the small boats of the fishermen, so that we had to retrieve environmental data from an online database, and estimate the corresponding dose in the period worked by the fishermen. Moreover, in the database we selected there was no availability of ambient data referred to the place where we actually performed the measurements $\left(43^{\circ} 9^{\prime} \mathrm{N}, 12^{\circ} 7^{\prime} \mathrm{E}\right)$, so that we considered available data for the city of Venice (about $200 \mathrm{~km}$ in the northern-east direction, at a slightly higher latitude and similar altitude).

Finally, we want to mention also some possible limitations related to the placement of the dosimeters on the workers. Unfortunately, we were not able to "a priori" select the most appropriate body districts where to fix the dosimeters according to the specific working tasks of the workers with respect to solar UVR 
exposure. On the contrary, as this was an on-field measurements campaign during real working situations, we had to place the dosimeters in positions selected as the best compromise between an appropriate evaluation of the personal exposure and the need of not interfering with the usual job activities of the workers. Accordingly, we decided to place the dosimeters mainly at the upper back for fishermen and dockworkers employed as longshoremen, while at the chest for the dockworkers performing as traffic coordinators of the port area. In the few cases we had for the same workers both the data from the back dosimeter and the data from other body districts (chest, and in one case also the nape), the upper back resulted the district with the highest exposure levels.

\section{Conclusions}

In conclusion, our data are, to the best of our knowledge, the first Italian data demonstrating with on field measurements an intense solar UVR dose received by fishermen and dockworkers in the spring and summer seasons. According to the photo-chemical effect of the UV rays absorbed in the skin, these data indicate an excessive occupational risk, possibily resulting after years of work in an increased occurrence of skin pre-cancerous and cancerous lesions. Therefore, there is an urgent need of sun-safety campaigns for outdoor workers, in particular for those of the maritime and port sectors, as we found no previous reporting of such campaigns for these workers in scientific literature. We offered a sun-safety training to the workers we investigated with dosimeters for their personal solar UVR exposure. Before the training, workers reported very poor sun exposure habits and behaviours. After our training, fishermen reported an improvement in the use of individual UV protections, as hat, sunglasses and clothes. Unfortunately, no positive improvements have been found with respect to the use of sunscreens at work in these workers.

\section{Conflict of Interest}

The authors declare no conflict of interest.

\section{Acknowledgments}

For the kind collaborations permitting us to conduct this research, we are very grateful to the dockworkers company, to the Port Authority and to the Prevention Department - Occupational Medicine section of the city of Trieste. We are very grateful also to the fishermen company "Casa del Pescatore" of Cattolica, to the Port Authorities and the Coasts Guards of Cattolica and Rimini, to the Ruggieri's family and to the occupational medicine service "Studio Manini".

\section{References}

[1] A. Modenese, F. Bisegna, M. Borra, C. Burattini, L. Gugliermetti, F.L. Filon, A. Militello, P. Toffanin, F. Gobba, "Occupational Exposure to Solar UV Radiation in a Group of Dock-workers in North-East Italy," Proceedings 2020 IEEE International Conference on Environment and Electrical Engineering and 2020 IEEE Industrial and Commercial Power Systems Europe, EEEIC / I and CPS Europe 2020, 2020, doi:10.1109/EEEIC/ICPSEurope49358.2020.9160703.

[2] A. Modenese, F.P. Ruggieri, F. Bisegna, M. Borra, C. Burattini, E. Della Vecchia, C. Grandi, A. Grasso, L. Gugliermetti, M. Manini, A. Militello, F. Gobba, "Occupational exposure to solar UV radiation of a group of fishermen working in the Italian north adriatic sea," International Journal of Environmental Research and Public Health, 16(16), 1-12, 2019, doi:10.3390/ijerph16163001.
[3] T. Kauppinen, J. Toikkanen, A. Savela, D. Pedersen, R. Young, W. Ahrens, P. Boffetta, M. Kogevinas, J. Hansen, H. Kromhout, V. de La Orden-Rivera, J. Maqueda Blasco, D. Mirabelli, B. Pannett, N. Plato, R. Vincent, "Occupational exposure to carcinogens in the European Union," Occupational and Environmental Medicine, 57(1), 10-18, 2000, doi:10.1136/oem.57.1.10.

[4] T. Loney, M.S. Paulo, A. Modenese, F. Gobba, T. Tenkate, D.C. Whiteman, A.C. Green, S.M. John, "Global evidence on occupational sun exposure and keratinocyte cancers: a systematic review," British Journal of Dermatology, 1-11, 2020, doi:10.1111/bjd.19152.

[5] B.K. Armstrong, A.E. Cust, "Sun exposure and skin cancer, and the puzzle of cutaneous melanoma: A perspective on Fears et al. Mathematical models of age and ultraviolet effects on the incidence of skin cancer among whites in the United States. American Journal of Epidemiology 1977" Cancer Epidemiology, 48, 147-156, 2017, doi:10.1016/j.canep.2017.04.004.

[6] J.C.S. Yam, A.K.H. Kwok, "Ultraviolet light and ocular diseases," International Ophthalmology, 34(2), 383-400, 2014, doi:10.1007/s10792013-9791-x.

[7] K. Grandahl, J. Olsen, K.B.E. Friis, O.S. Mortensen, K.S. Ibler, "Photoaging and actinic keratosis in Danish outdoor and indoor workers," Photodermatology Photoimmunology and Photomedicine, 35(4), 201-207, 2019, doi:10.1111/phpp.12451.

[8] G. Ziegelberger, "Icnirp statement-protection of workers against ultraviolet radiation," Health Physics, 99(1), 66-87, 2010 , doi:10.1097/HP.0b013e3181d85908.

[9] R.R.A. Bourne, J.B. Jonas, A.M. Bron, M.V. Cicinelli, A. Das, S.R. Flaxman, D.S. Friedman, J.E. Keeffe, J.H. Kempen, J. Leasher, H. Limburg, K. Naidoo, K. Pesudovs, T. Peto, J. Saadine, A.J. Silvester, N. Tahhan, H.R. Taylor, R. Varma, T.Y. Wong, S. Resnikoff, "Prevalence and causes of vision loss in high-income countries and in Eastern and Central Europe in 2015: Magnitude, temporal trends and projections," British Journal of Ophthalmology, 102(5), 575-585, 2018, doi:10.1136/bjophthalmol-2017311258.

[10] A. Modenese, F. Gobba, "Cataract frequency and subtypes involved in workers assessed for their solar radiation exposure: a systematic review," Acta Ophthalmologica, 96(8), 2018, doi:10.1111/aos.13734.

[11] A. Modenese, F. Gobba, "Occupational exposure to solar radiation at different latitudes and pterygium: A systematic review of the last 10 years of scientific literature," International Journal of Environmental Research and Public Health, 15(1), 2018, doi:10.3390/ijerph15010037.

[12] A. Modenese, F. Gobba, "Macular degeneration and occupational risk factors: a systematic review," International Archives of Occupational and Environmental Health, 92(1), 2019, doi:10.1007/s00420-018-1355-y.

[13] U. Feister, G. Meyer, U. Kirst, "Solar UV exposure of seafarers along subtropical and tropical shipping Routes," Photochemistry and Photobiology, 89(6), 1497-1506, 2013, doi:10.1111/php.12144.

[14] K. Grandahl, P. Eriksen, K.S. Ibler, J.P. Bonde, O.S. Mortensen, "Measurements of Solar Ultraviolet Radiation Exposure at Work and at Leisure in Danish Workers," Photochemistry and Photobiology, 94(4), 807814, 2018, doi:10.1111/php.12920.

[15] M. Oldenburg, B. Kuechmeister, U. Ohnemus, X. Baur, I. Moll, "Actinic keratosis among seafarers," Archives of Dermatological Research, 305(9), 787-796, 2013, doi:10.1007/s00403-013-1384-z.

[16] K. Grandahl, K.S. Ibler, G.H. Laier, O.S. Mortensen, "Skin cancer risk perception and sun protection behavior at work, at leisure, and on sun holidays: A survey for Danish outdoor and indoor workers 11 Medical and Health Sciences 1117 Public Health and Health Services," Environmental Health and Preventive Medicine, 23(1), 1-11, 2018, doi:10.1186/s12199018-0736-x.

[17] F. Larese Filon, M. Buric, C. Fluehler, "UV exposure, preventive habits, risk perception, and occupation in NMSC patients: A case-control study in Trieste (NE Italy)," Photodermatology Photoimmunology and Photomedicine, 35(1), 24-30, 2019, doi:10.1111/phpp.12417.

[18] A. Modenese, T. Loney, F.P. Ruggieri, L. Tornese, F. Gobba, "Sun protection habits and behaviors of a group of outdoor workers and students from the agricultural and construction sectors in north-Italy," Medicina Del Lavoro, 111(2), 116-125, 2020, doi:10.23749/mdl.v111i2.8929.

[19] M.M. Nkogatse, M.C. Ramotsehoa, F.C. Eloff, C.Y. Wright, "Solar Ultraviolet Radiation Exposure and Sun Protection Behaviors and Knowledge Among a High-Risk and Overlooked Group of Outdoor Workers in South Africa," Photochemistry and Photobiology, 95(1), 439-445, 2019, doi:10.1111/php.13008.

[20] C.E. Peters, M.W. Koehoorn, P.A. Demers, A.M. Nicol, S. Kalia, "Outdoor Workers' Use of Sun Protection at Work and Leisure," Safety and Health at Work, 7(3), 208-212, 2016, doi:10.1016/j.shaw.2016.01.006. 
[21] D. Reinau, M. Weiss, C.R. Meier, T.L. Diepgen, C. Surber, "Outdoor workers' sun-related knowledge, attitudes and protective behaviours: A systematic review of cross-sectional and interventional studies," British Journal of Dermatology, 168(5), 928-940, 2013, doi:10.1111/bjd.12160.

[22] S. Schneider, K. Diehl, L. Schilling, M. Spengler, R. Greinert, T. Görig, "Occupational UV exposure and sun-protective behaviour in German outdoor workers: Results of a nationwide study," Journal of Occupational and Environmental Medicine, 60(11), 961-967, 2018, doi:10.1097/JOM.0000000000001397.

[23] M. Boniol, A. Koechlin, M. Boniol, F. Valentini, M.C. Chignol, J.F. Doré, J.L. Bulliard, A. Milon, D. Vernez, "Occupational UV exposure in French outdoor workers," Journal of Occupational and Environmental Medicine, 57(3), 315-320, 2015, doi:10.1097/JOM.0000000000000354.

[24] P. Gies, J. Wright, "Measured Solar Ultraviolet Radiation Exposures of Outdoor Workers in Queensland in the Building and Construction Industry f," Photochemistry and Photobiology, 78(4), 342, 2003, doi:10.1562/00318655(2003)078<0342:msureo $>2.0$.co;2.

[25] V. Hammond, A.I. Reeder, A. Gray, "Patterns of real-time occupational ultraviolet radiation exposure among a sample of outdoor workers in New Zealand," Public Health, 123(2), 182-187, 2009, doi:10.1016/j.puhe.2008.12.007.

[26] M. Antoine, S. Pierre-Edouard, B. Jean-Luc, V. David, "Effective exposure to solar UV in building workers: Influence of local and individual factors," Journal of Exposure Science and Environmental Epidemiology, 17(1), 5868, 2007, doi:10.1038/sj.jes.7500521.

[27] M.A. Serrano, J. Cañada, J.C. Moreno, "Solar UV exposure in construction workers in Valencia, Spain," Journal of Exposure Science and Environmental Epidemiology, 23(5), 525-530, 2013, doi:10.1038/jes.2012.58.

[28] M. Wittlich, S.M. John, G.S. Tiplica, C.M. Sălăvăstru, A.I. Butacu, A. Modenese, V. Paolucci, G. D'Hauw, F. Gobba, P. Sartorelli, J. Macan, J. Kovačić, K. Grandahl, H. Moldovan, "Personal solar ultraviolet radiation dosimetry in an occupational setting across Europe," Journal of the European Academy of Dermatology and Venereology, 34(8), 1835-1841, 2020, doi:10.1111/jdv.16303. 